\title{
Complete evulsion of the globe and optic nerve
}

\author{
SASIKALA PILlAi, MUNEERA A MAHMOOD, AND SURESH R LIMAYE \\ From the District of Columbia General Hospital, Ophthalmology Service, 19th Street and Massachusetts \\ Avenue, SE, Room 3325, Washington, DC 20003, and Georgetown University Medical Center, Center for \\ Sight, Department of Ophthalmology, 3800 Reservoir Road, NW, Washington, DC 20007, USA
}

SUMmary A 17-year-old boy had an evulsion of globe and optic nerve from an automobile accident. Computed tomography showed a severed optic nerve on the injured side. A visual field defect was demonstrated in the other eye.

Optic nerve injuries may occur from direct or indirect injuries to the orbital region. ${ }^{12}$ An unusual case of evulsion of the globe and optic nerve with field defect in the other eye from an automobile accident is reported. The mechanisms, early diagnosis, and management of optic nerve injuries are discussed.

\section{Case report}

A 17-year-old boy was brought to the Emergency Room after an automobile accident. He was thrown through the windscreen of the car, approximately 20 feet $(6 \mathrm{~m})$ on to the pavement. The patient was unconscious and could be aroused to painful stimuli only. He had a closed head injury with cerebral oedema and acute respiratory distress syndrome, for which cricothyroidectomy was done. His right globe was outside the orbit with the lids tightly closed behind it (Fig. 1). Vision could not be assessed. On the right side there was marked lid oedema, the cornea was clear, the anterior chamber had a $25 \%$ hyphaema, and the pupil was $7 \mathrm{~mm}$ in size, round and non-reactive. There was no laceration of cornea or sclera. The fundus could not be visualised. The left eye was normal. A CT scan showed a small left subdural haemorrhage with cerebral oedema and shift of midline structures to the right. There was haemorrhage within the orbit posterior to the globe. The patient received intravenous mannitol, dexamethasone, frusemide, and cefapirin. Four hours after the accident a right lateral canthotomy was done, but the globe could not be reposited in the orbit. Two hours after treatment with ice packs and

Correspondence to Sasikala Pillai, MD, DC General Hospital, Ophthalmology Service, 19th Street and Massachusetts Avenue SE, Washington, DC 20003, USA. keeping the eye in a moist chamber the globe was reposited in the orbit with considerable difficulty, and a complete tarsorrhaphy was done.

For five days the patient was medically and neurologically unstable. He regained consciousness, and it was then found that he had no vision in the right eye. A day later he had tenderness over the right upper lid, and the possibility of an orbital abscess was entertained. He was transferred to the Ophthalmology Department. A CT scan of the orbit done at this time showed no haemorrhage or abscess within the orbit. However, there was evulsion of the optic nerve on the right side (Fig. 2). The tarsorrhaphy was then opened. There was no light perception in the right eye. The eye was proptosed and exotropic, with marked limitation of extraocular movements in all directions of gaze. There was blood staining of the cornea. Details of the anterior chamber and fundus

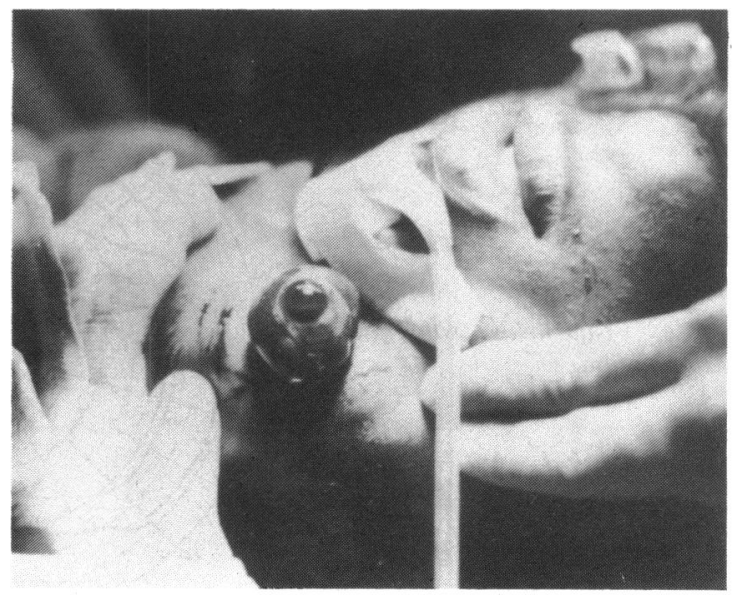

Fig. 1 Appearance of the eye at initial presentation. 


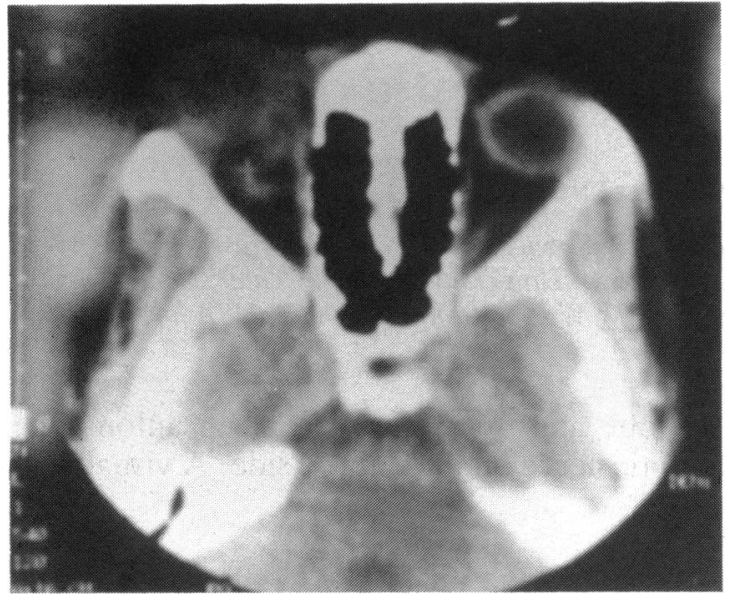

Fig. 2 CT scan showing severed optic nerve on the right side.

were not visible. The left eye had $20 / 20$ vision and the examination gave normal results.

Fifteen days after the accident the right eye was enucleated. At surgery there was a horizontal lacera- tion in the conjunctiva inferiorly $6-8 \mathrm{~mm}$ below the limbus extending across the whole length of the palpebral fissure. The inferior rectus muscle had been disinserted and was reattached to the globe 20 $\mathrm{mm}$ posterior to the limbus. The optic nerve had been transected $31 \mathrm{~mm}$ behind the globe. The postoperative course was uneventful. Goldmann perimetry in the left eye, done after surgery, showed a relative depression of $\mathrm{I} 2 \mathrm{e}$ and II $2 \mathrm{e}$ isoptres in the superior temporal quadrant (Fig. 3). The visual fields showed improvement when repeated after five months (Fig. 4).

\section{Discussion}

The word 'evulsion' stems from the latin ' $e$ ' (out) and 'vellere' (to pluck) and the word 'avulsion' is derived from the latin 'a' (away) and 'vellere'. These terms have been used interchangeably by most authors. Salzmann ${ }^{3}$ defined 'avulsion' of the optic nerve as 'the forceful backward dislocation of the optic nerve from the scleral canal without any break in continuity of the adjacent coats of the globe.'

Lister ${ }^{4}$ and Walsh and Hoyt ${ }^{5}$ stated that the blow
Fig. 3 Visual fields at initial examination.
Fig. 4 Visual fields at subsequent examination.
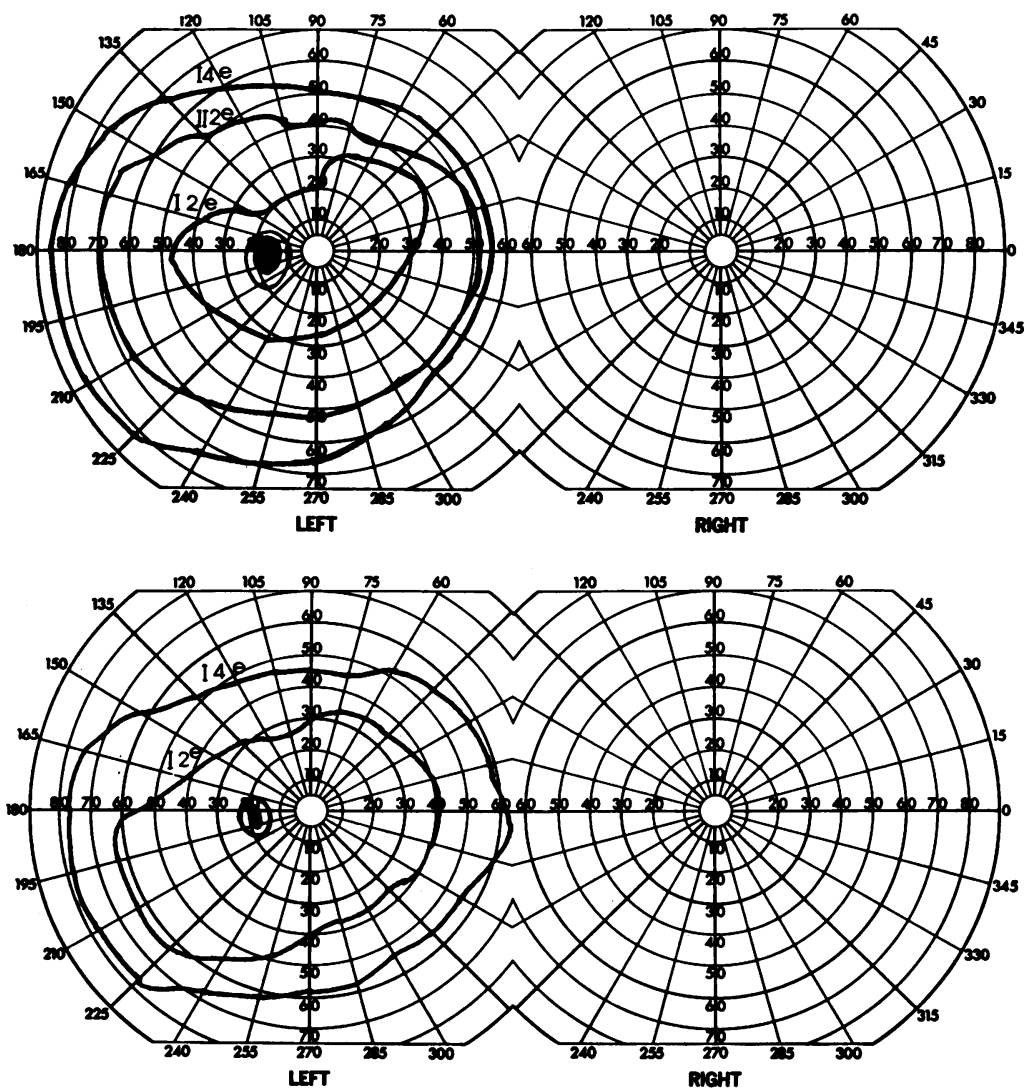
on the front of the eye produced a sudden increase in intraocular pressure which ruptured the lamina cribrosa and expelled the nerve. Lowenstein ${ }^{6}$ postulated that rupture of the optic nerve occurred at the lamina cribrosa because of anatomical weakness of that region. The posterior portion of the lamina cribrosa is one-third the thickness of the surrounding sclera, and the optic nerve fibres are not supported by myelin or connective tissue septa in this part of the nerve. He also noted that the optic sheath usually remained attached to the globe since it is more elastic than the optic nerve. Lagrange's ${ }^{7}$ theory of optic nerve injury was that indirect facial injury set up concussion waves which travelled through the pterygo-maxillary fissure into the orbit and the globe was then propelled forward, stretching the nerve causing evulsion.

The optic nerve can be involved in injuries over the fronto-orbital region ${ }^{8}$ or even after trivial injuries like a finger or stick entering the orbit tangentially, either penetrating or leaving the conjunctiva intact. ${ }^{9-12}$ In Turner' ${ }^{13}$ series the frequency of complete or incomplete injuries of the optic nerve was about $1.5 \%$. Only injuries to the olfactory and facial nerves were commoner than those to the optic nerves. Damage to the optic chiasm can occur with fronto-orbital injuries. Traquair et al. ${ }^{14}$ considered that with these injuries there was interruption of vascular supply to the chiasm. These vessels are attached to the base of the skull, and movement of the chiasm and brain could cause laceration or thrombosis, with subsequent softening of the chiasm. Trauma to the optic nerve can result in intrasheath haemorrhage, oedema, contusion, avulsion, or evulsion of the nerve. The visual loss might be sudden and permanent, sudden with gradual partial recovery, or chronic and progressive. Other ocular findings associated with optic nerve injury may be subconjunctival haemorrhage, limitation of extraocular movement, dilated fixed pupil, and proptosis. In avulsion of optic nerve the fundus may show haemorrhage fanning out from the disc, with an elliptical excavated defect in the disc. This defect would be later filled with gliotic tissue, which may extend into, the vitreous. Extensive vitreous haemorrhage may delay or prevent the diagnosis in the early stages of optic nerve injury, and the later stages may be confused with a developmental anomaly. ${ }^{15}$ Visual field defects may vary from concentric contraction to sectorial involvement.

The treatment of optic nerve injuries is controversial. Those who advocate massive dosage of steroids believe that it decreases the swelling of the optic nerve in the optic canal and thereby partly or completely restores vision. Panje et al. ${ }^{16}$ recommend giving $1 \mathrm{mg}$ Decadron (dexamethasone) per $\mathrm{kg}$ body weight initially, then $0.5 \mathrm{mg}$ per kg every six hours for 24 hours, and then $1 \mathrm{mg}$ per $\mathrm{kg}$ per day for one to two days. If no response occurs within 48 hours, therapy should be stopped. If the patient does respond, this dose is continued for five days and then rapidly tapered. If visual acuity fails while the patient is on steroid, Panje et al. ${ }^{16}$ suggest operative intervention. Surgical intervention consists in decompression of the optic nerve, which can be achieved by transorbital, transethmoidal, or transantral approaches. Fukado ${ }^{17}$ popularised the transethmoidal approach and had spectacular results with it. The decision to intervene surgically in optic nerve damage is a difficult one. Walsh and Hoyt ${ }^{5}$ stated that, if the loss of vision or abnormal pupillary response to light developed within minutes after the injury, the possibility of surgical intervention should be considered in order to halt further visual deterioration.

Our patient sustained a severe concussive injury to the orbit. This probably resulted in forward propulsion of the globe, and the retrobulbar haemorrhage which occurred caused rapid proptosis. This may have resulted in the lids getting caught behind the globe. The laceration in the inferior conjunctiva, with disinsertion of inferior rectus, might have been caused by a sliver of glass from the windscreen. The optic nerve might have been cut by the same piece of glass, as the globe was suddenly pushed forwards, or it might have been evulsed. The site of injury as far back as the optic chiasm resulted in injury to the anterior loop of crossed fibres from the opposite nerve, causing a relative field defect in the superior temporal quadrant of the eye. Traquair et al. ${ }^{14}$ considered that with fronto-orbital injuries there was movement of the chiasm and the brain, and this might have occurred in our patient. As the oedema round the chiasm subsided, the visual field in the left eye showed improvement.

To our knowledge no other case has been described in which an evulsion of the globe and optic nerve from the orbit resulted from trauma and field defects occurred in the other eye. The only analogy which can be drawn with our case is in cases of autoenucleation where the globe and optic nerve have been evulsed from the orbit, resulting in visual field defect in the remaining eye. In the case of Krauss $\mathrm{et} \mathrm{al} .{ }^{18}$ there was a $44 \mathrm{~mm}$ attached segment of the optic nerve, and the patient had temporal hemianopsia of the remaining eye. The diagnosis of injuries to the optic nerve by either direct or indirect trauma depends on careful examination of visual acuity, the visual fields, and the pupillary reflexes. Frequent evaluation of visual acuity is necessary to decide if surgical intervention is required. The role of massive dose of steroids in reversing optic nerve damage is controversial. 


\section{References}

1 Habal MB. Clinical observations on the isolated optic nerve injury. Ann Plast Surg 1978; 6: 603-7.

2 Runyan TE. Concussive and penetrating injuries of the globe and optic nerve. St Louis: Mosby, 1975: 149-64.

3 Salzmann M. Die Ausreissung des Sehnerven (evulsio nervi optici) Z Augenheilkd 1903; 26: 489-505.

4 Lister $W$. Some concussion changes met with in military practice. Br J Ophthalmol 1924; 8: 305-18.

5 Walsh FB, Hoyt WF. Involvement of the optic nerves in closed head injuries: indirect optic nerve injuries. Clinical neuroophthalmology. Baltimore: Williams and Wilkins, 1969: 237581.

6 Lowenstein A. Marginal haemorrhage on the disc. Partial cross tearing of the optic disc. Clinical and histological findings. $\mathrm{Br} \mathrm{J}$ Ophthalmol 1943; 27: 208-15.

7 Lagrange F. Les fractures de l'orbite par les projectiles de guerre. Paris: Masson, 1917.

8 Venable PH, Wison S, Allan WC, Prensky AL. Total blindness after trivial frontal head trauma: bilateral indirect optic nerve injury. Neurology (NY) 1978; 10: 1066-8.

9 Duke-Elder S. Mechanical injuries. System of ophthalmology. St Louis: Mosby, 1972: 14(1): 187-94.
10 Park JH, Frenkel M, Dobbie JG, Chromokos E. Evulsion of the optic nerve. Am J Ophthalmol 1971; 71: 969-71.

11 Spizziri LJ. Avulsion of optic nerve. Report of a case. Am J Ophthalmol 1964; 58: 1056-9.

12 Chow AY, Goldberg MF, Frenkel M. Evulsion of the optic nerve in association with basketball injuries. Ann Ophthalmol 1984; 16: 35-7.

13 Turner JWA. Indirect injuries of the optic nerve. Brain 1943; 66: $140-51$.

14 Traquair HM, Dott N, Russell WR. Traumatic lesions of the optic chiasma. Brain 1935; 52: 398-411.

15 Stanton-Cook L. Injury simulating congenital anomaly. $\mathrm{Br} \mathrm{J}$ Ophthalmol 1953; 37: 188-9.

16 Panje WR, Gross CE, Anderson RL. Sudden blindness following facial trauma. Otolaryngol Head Neck Surg 1981; 89: 941-8.

17 Fukado Y. Diagnosis and surgical correction of optic canal fracture after head injury. Ophthalmologica 1969; 158(suppl): 307-14.

18 Krauss HR, Yee RD, Foos RY. Autoenucleation. Surv Ophthalmol 1984; 29: 179-87.

Accepted for publication 1 April 1986. 